\title{
Reduction of Pyrrolizidine Alkaloid Levels in Comfrey (Symphytum officinale) Hairy Roots by RNAi Silencing of Homospermidine Synthase
}

Authors

Lars H. Kruse ${ }^{1,3}$, Thomas Stegemann ${ }^{1}$, Julia Jensen-Kroll ${ }^{1}$, Annika Engelhardt ${ }^{1}$, Anne-Maria Wesseling ${ }^{1}$, Annemarie Lippert ${ }^{2}$, Jutta Ludwig-Müller ${ }^{2}$, Dietrich Ober $^{1}$

\author{
Affiliations \\ 1 Botanisches Institut, Kiel University, Kiel, Germany \\ 2 Institut für Botanik, Technische Universität Dresden, \\ Dresden, Germany \\ 3 Plant Biology Section, School of Integrative Plant Science, \\ Cornell University, USA
}

Key words

Symphytum officinale, alkaloid extraction, transgenic tissue culture, transcript quantification, Boraginaceae

received May 6, 2019

revised August 5, 2019

accepted August 15, 2019

Bibliography

DOI https://doi.org/10.1055/a-0998-5125

Published online August 26, 2019 | Planta Med 2019; 85:

1177-1186 @ Georg Thieme Verlag KG Stuttgart · New York | ISSN 0032-0943

Correspondence

Prof. Dr. Dietrich Ober

Botanisches Institut, Kiel University

Am Botanischen Garten 1-9, 24118 Kiel, Germany

Phone: + 4943188042 99, Fax: + 494318804500

dober@bot.uni-kiel.de

Supporting information available online at

http://www.thieme-connect.de/products

\begin{abstract}
Comfrey is a medicinal plant, extracts of which are traditionally used for the treatment of painful inflammatory muscle and joint problems, because the plant contains allantoin and rosmarinic acid. However, its medicinal use is limited because of its toxic pyrrolizidine alkaloid (PA) content. PAs encompass more than 400 different compounds that have been identified from various plant lineages. To date, only the first pathwayspecific enzyme, homospermidine synthase (HSS), has been characterized. HSS catalyzes the formation of homospermidine, which is exclusively incorporated into PAs. HSS has been recruited several times independently in various plant lineages during evolution by duplication of the gene encoding deoxyhypusine synthase (DHS), an enzyme of primary metabolism. Here, we describe the establishment of RNAi knockdown hairy root mutants of HSS in Symphytum officinale. A knockdown of HSS by $60-80 \%$ resulted in a significant reduction of homospermidine by $\sim 86 \%$ and of the major PA components 7-acetylintermedine $\mathrm{N}$-oxide and 3-acetylmyoscorpine $\mathrm{N}$-oxide by approximately $60 \%$. The correlation of reduced transcript levels of HSS with reduced levels of homospermidine and PAs provides in planta support for HSS being the central enzyme in PA biosynthesis. Furthermore, the generation of PA-depleted hairy roots might be a cost-efficient way for reducing toxic by-products that limit the medicinal applicability of S. officinale extracts.
\end{abstract}

\section{Introduction}

Comfrey (Symphytum officinale L., Boraginaceae) has been used for many centuries as a medicinal plant to treat painful muscle and joint complaints [1]. Preparations of comfrey show anti-inflammatory and analgesic effects, stimulate granulation and tissue regeneration, support wound tissue formation, and have, therefore, been assessed positively by the German Commission $\mathrm{E}$ for the treatment of blunt injuries [2]. Allantoin and rosmarinic acid are thought to be part of the active principle, although the molecular mechanism of action is not understood in detail. However, the occurrence of PAs in all parts of $S$. officinale limits its ther- apeutic use to external applications. PAs are toxic after biotransformation by hepatic microsomal enzymes (P450 cytochrome monooxygenases), resulting in the formation of pyrrolic compounds that readily react with cellular structures such as DNA or proteins [3]. Strategies to reduce or eliminate PA levels in comfrey should result in improved comfrey preparations but necessitate a better understanding of the PA biosynthetic pathway.

Pathways of specialized metabolism are, in contrast to pathways of general metabolism, not ubiquitously found in plants and are often highly specific to a plant family, a genus, or even a single species $[4,5]$. PAs are a good example of a diverse group of secondary metabolites. More than 400 structures of PAs have 


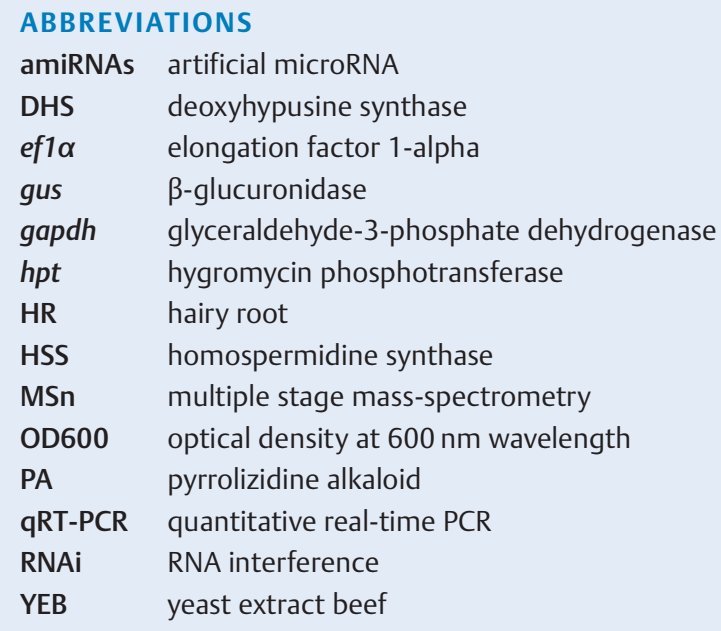

been described and are found in a number of angiosperm families (e.g., Asteraceae, Boraginaceae, Convolvulaceae, and Fabaceae) and several other plant families including the monocot families Poaceae and Orchidaceae [6,7]. Most PAs are toxic plant secondary metabolites produced as part of a chemical defense mechanism against herbivores. Their backbone structure consists of a necine base, which is esterified with 1 or more necic acids [8]. To date, only the first pathway-specific enzyme, HSS, has been identified. HSS transfers the aminobutyl moiety of spermidine to putrescine resulting in the formation of homospermidine ( $\bullet$ Fig. 1). The PA precursor homospermidine is exclusively incorporated in the necine base backbone of PAs [9]. HSS evolved by the duplication of the gene that encodes DHS of primary metabolism and that is involved in the post-translational activation of the eukaryotic initiation factor $5 A[10,11]$. HSS has evolved several times independently in various plant lineages that are able to produce PAs [12-14]. Methods to conduct loss-of-function experiments by gene knockdown include RNA silencing (RNA interference, RNAi) or amiRNAs. RNAi has been successfully applied to an array of genes in species of model and non-model plants [15-18], whereas amiRNAs have so far only been used in a limited number of species including Arabidopsis thaliana L., Brassicaceae [19]. To facilitate RNAi studies in a plant of interest, a method for stable transformation has to be available, such as infection with Agrobacterium [20,21]. Infection of a plant with Agrobacterium rhizogenes (Riker), Rhizobiaceae, induces the so-called "hairy root disease," leading to the growth of artificial roots with indefinite growth, a strong branching pattern, and an often-enhanced production of secondary metabolites at the site of infection [22-25].

Here, we report the successful RNAi-mediated knockdown of HSS in S. officinale by means of HRs generated by transformation with A. rhizogenes. We show, by qRT-PCR and LC-MS-based PA quantification, that low transcript levels of HSS correlate with reduced levels of homospermidine and PAs. These results are the first in planta evidence for the involvement of HSS in the biosynthesis of PAs and should open up possibilities for developing improved comfrey products (i.e., by the reduction of toxic PAs).

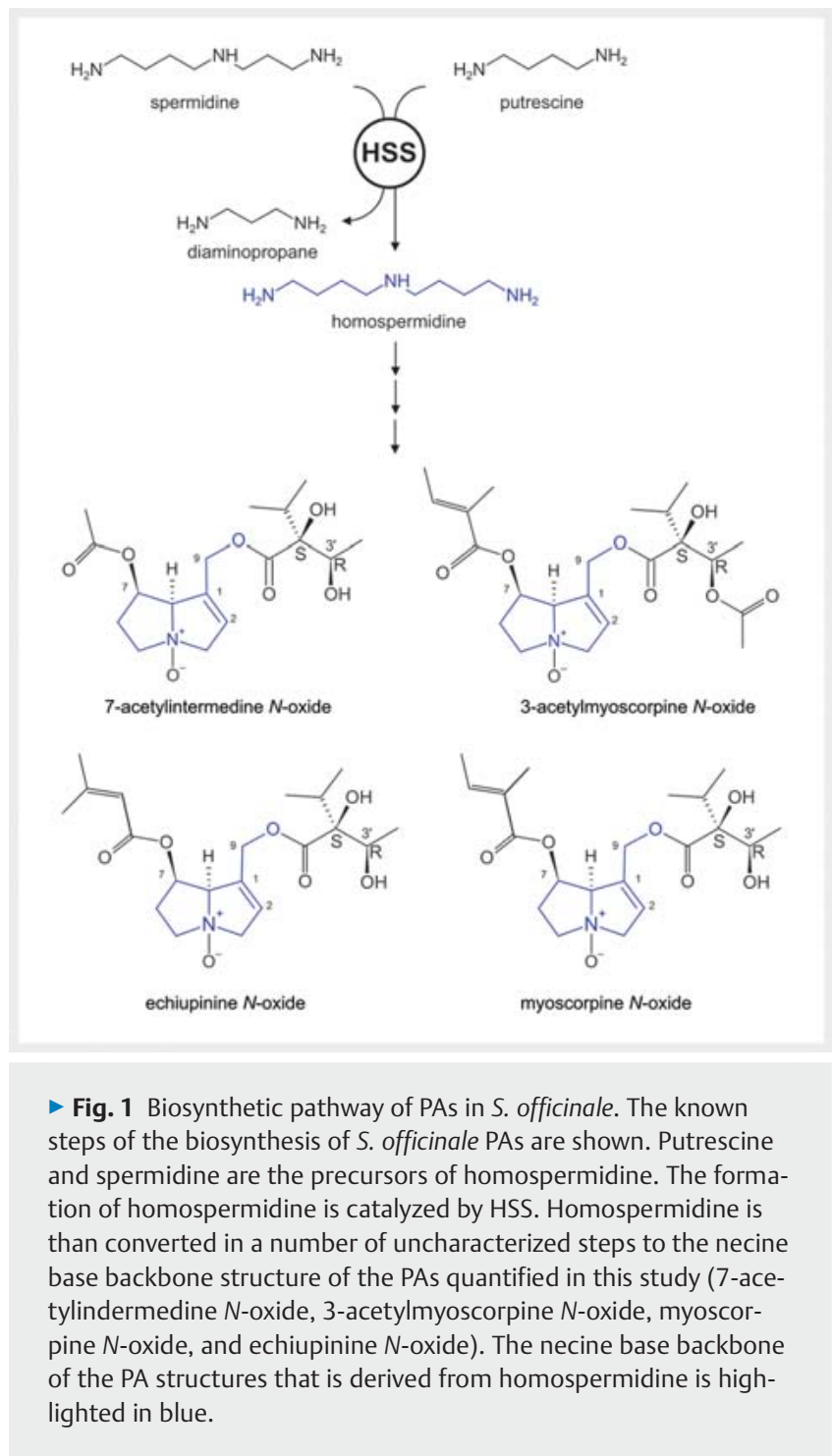

\section{Results}

Several possibilities are available for the downregulation of transcripts in plants, such as RNAi or amiRNAs. In order to examine the effect of HSS knockdown in S. officinale HRs, we generated several independent transgenic HR lines. To determine the best possible method for comfrey, we compared amiRNA and RNAi approaches in preliminary experiments. For this purpose, we infected leaf explants with an $A$. rhizogenes strain that harbored the binary PH7GWIWG2(II) plasmid containing a 226 bp part of the coding region of $S$. officinale HSS covering the end of the open reading frame and parts of the $3^{\prime}$ untranslated region in the sense and anti-sense directions to allow the transcription of a RNA hairpin structure. HRs expressing this construct should have reduced HSS transcript levels that should result in decreased levels of homospermidine and PAs. In addition, we generated amiRNA constructs based on the Web MicroRNA Designer (WMD3, http:// wmd3.weigelworld.org/cgi-bin/webapp.cgi) [26]. Only 1 group of independent HR transformants containing an amiRNA con- 


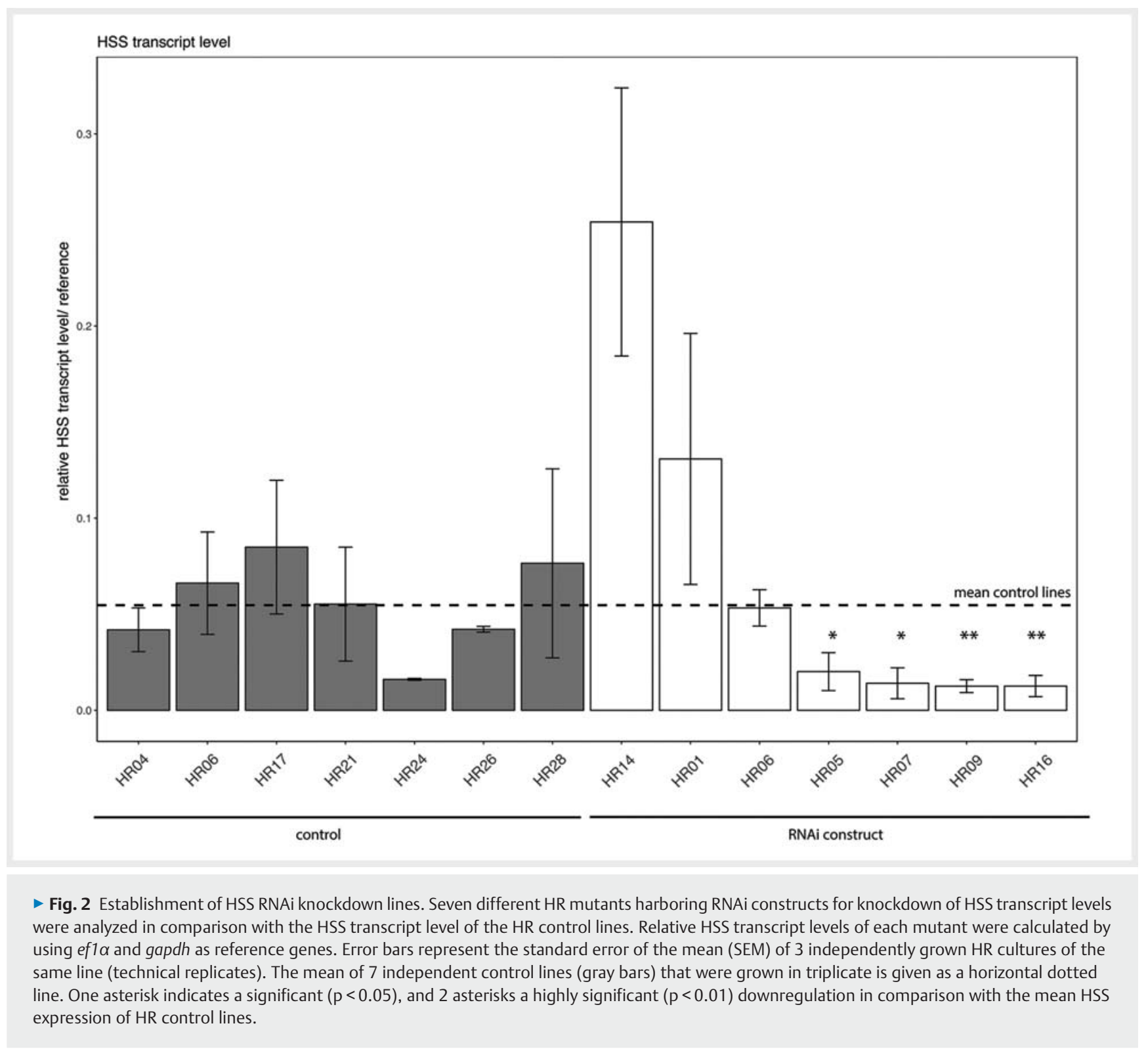

struct (ami2) showed consistently reduced HSS transcript and PA levels (Fig. 1S, Supporting Information), whereas for a second amiRNA (ami1a), we detected only 3 independent transformants with the desired molecular and phytochemical phenotype, and for a third (ami4a), no consistent downregulation of the HSS transcript was observed. Therefore, we decided to continue with the RNAi lines.

To test whether the generated RNAi lines showed the downregulation of the target gene encoding HSS, we quantified HSS transcript levels of 7 mutant HR lines that resulted from independent transformation events in comparison with $7 \mathrm{HR}$ control lines that resulted from transformation with the same vector that contained the gus gene instead of a specific RNAi construct. HSS transcript levels were quantified by qRT-PCR with gapdh and ef $1 \alpha$ as reference genes. Four HSS knockdown mutants showed a significant downregulation of HSS transcript level to $23-37 \%$ of the mean of the control lines (HR05, HR07, HR09, and HR16;

- Fig. 2). These 4 mutant lines were chosen to serve as biological replicates for an RNAi knockdown of HSS in the following analysis. Mutants that showed an upregulation or no significant downregulation of HSS transcript levels were excluded from the following analyses (HR01, HR06, and HR14; > Fig. 2). We compared the mean HSS transcript level of RNAi mutants with that of the control lines and found HSS expression to be significantly reduced in the 4 chosen RNAi mutant lines ( $p=0.003$, > Fig. 3 A).

In order to test the effects of HSS downregulation, we quantified homospermidine levels in RNAi-lines and control lines by HPLC analyses. Homospermidine levels were found to be significantly (hedge's $g=3.88, p=0.0002$, Fig. 3 B) lower in HSS knockdown mutants (average $=3.14 \mathrm{nmol} / \mathrm{g}$ ) than in control HRs (average $=29.00 \mathrm{nmol} / \mathrm{g}$ ) -that is, the content of homospermidine in RNAi knockdown lines was reduced by $93 \%$ in comparison with 


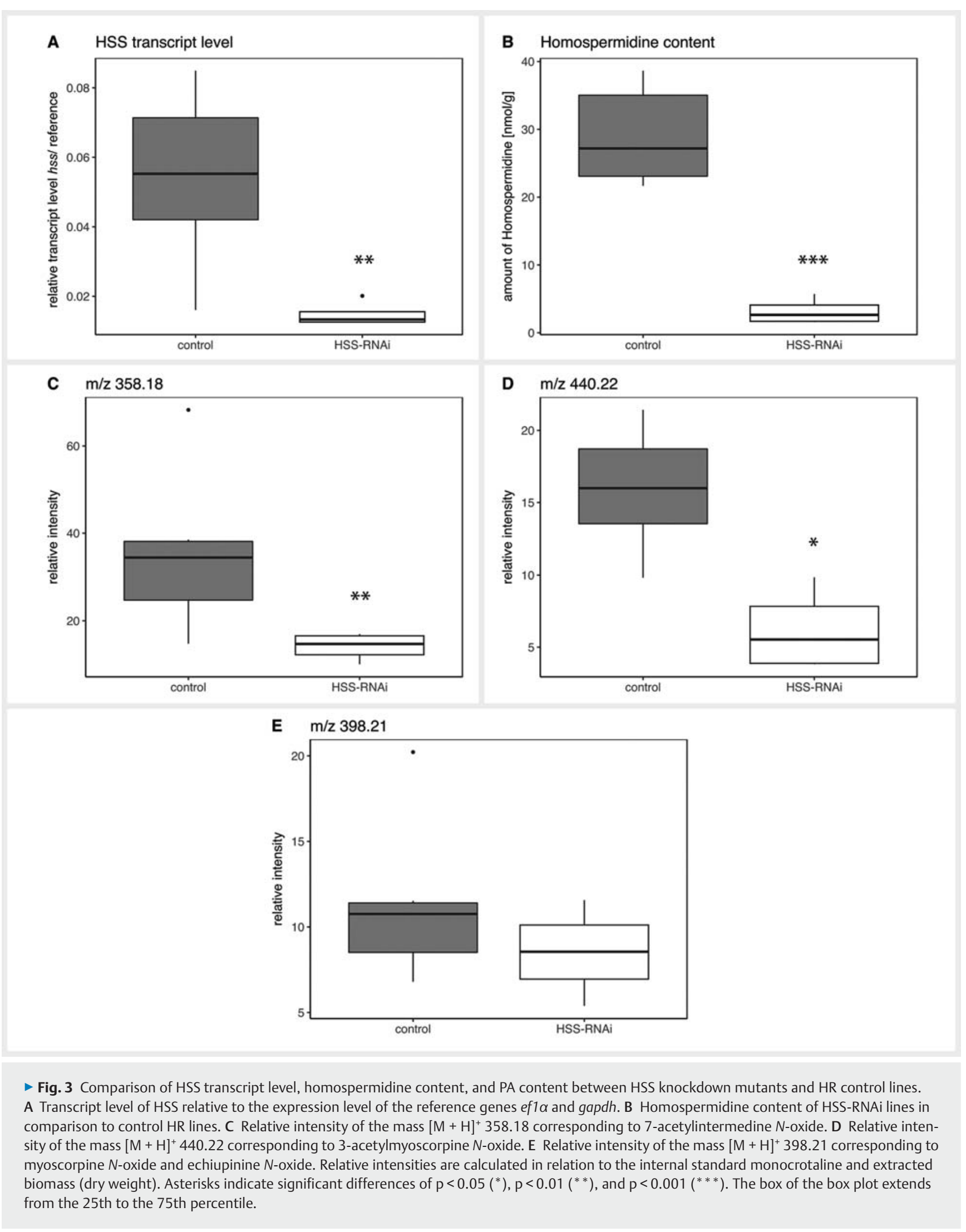




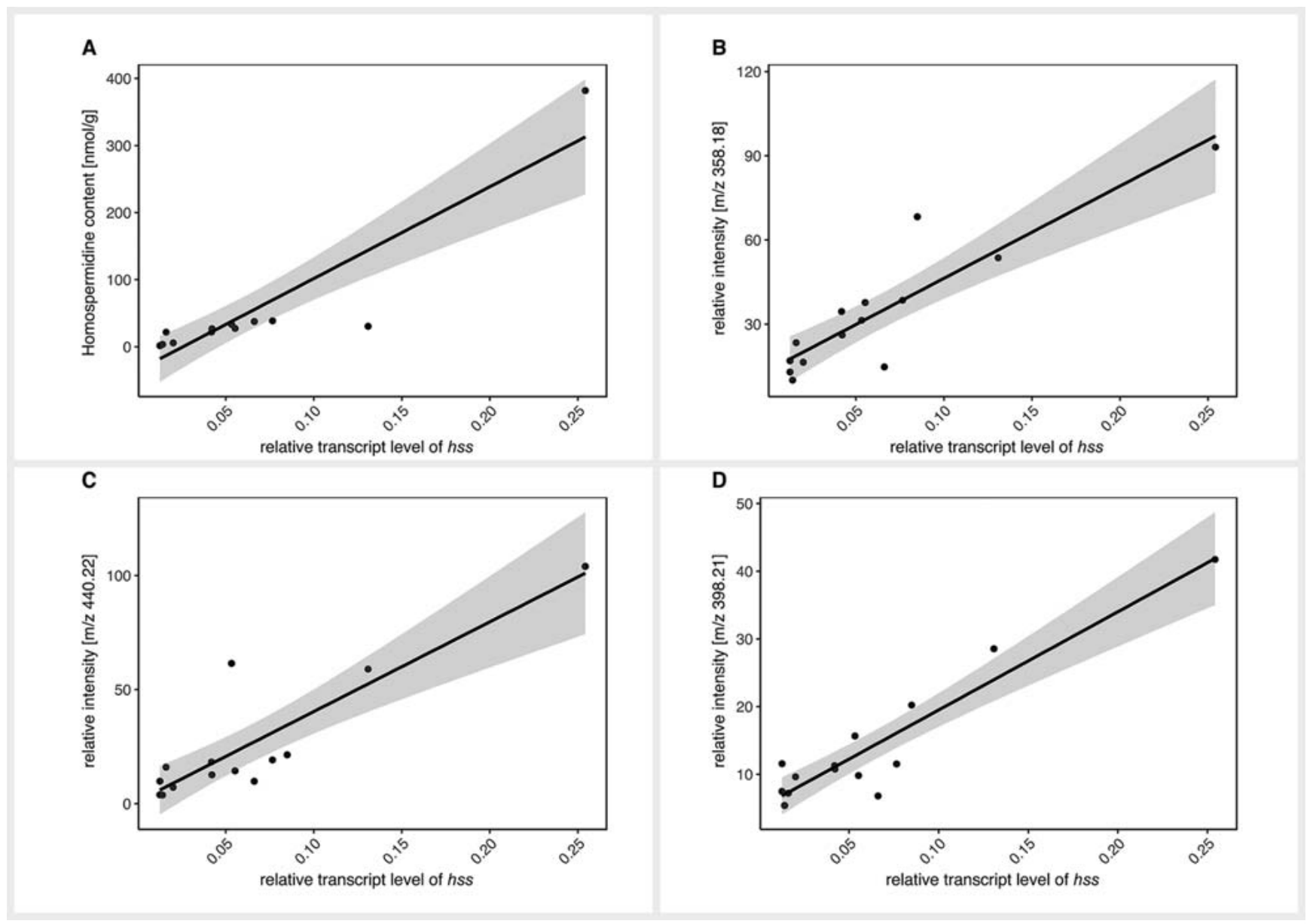

- Fig. 4 Correlation between HSS transcript level and relative intensity of specific masses characteristic for PAs. A Homospermidine content versus relative transcript level of HSS in HRs harboring an HSS-specific RNAi construct and control lines ( $p<0.05$, Pearson's product-moment coefficient $=0.68)$. B Relative intensity of the mass $[\mathrm{M}+\mathrm{H}]^{+} 358.18$ corresponding to 7 -acetylintermedine $\mathrm{N}$-oxide versus transcript level of HSS $(\mathrm{p}<0.0001$, Pearson's product-moment coefficient $=0.85)$. C Relative intensity of mass $[\mathrm{M}+\mathrm{H}]^{+} 440.22$ corresponding to 3 -acetylmyoscorpine $\mathrm{N}$-oxide versus HSS transcript level $(\mathrm{p}<0.001$, Pearson's product-moment coefficient $=0.82)$. D Relative intensities of the mass $[\mathrm{M}+\mathrm{H}]^{+} 398.21$ corresponding to myoscorpine $\mathrm{N}$-oxide and echiupinine $\mathrm{N}$-oxide versus HSS transcript level $(\mathrm{p}<0.001$, Pearson's product-moment coefficient = 0.79). Relative intensities are calculated in relation to the internal standard monocrotaline and extracted biomass (dry weight). Gray-shaded areas indicate the $95 \%$ confidence interval of the linear model used to fit the line. Relative HSS transcript levels were calculated with gapdh and ei1 $\alpha$ as reference genes.

the control lines. Homospermidine content was strongly correlated with HSS transcript level in the analyzed HRs (control lines and lines transformed with the RNAi construct, $p<0.05$, Pearson's product-moment coefficient $=0.68$, $>$ Fig. $4 \mathrm{~B}$ ). The strong reduction of homospermidine levels upon successful knockdown of HSS and the tight correlation of HSS and homospermidine demonstrate the importance of HSS in producing the sole precursor of PA biosynthesis and suggest that the plant lacks alternative biosynthetic routes to produce homospermidine.

To test our hypothesis that reduced homospermidine levels correlate with reduced PA levels, we quantified PAs of RNAi mutants and control lines by LC-ESI-MS and subsequent broadband MSn fragmentation. Analyzing 3 representative masses $[\mathrm{M}+\mathrm{H}]^{+}$ 358.18, $[\mathrm{M}+\mathrm{H}]^{+}$398.21, $[\mathrm{M}+\mathrm{H}]^{+}$440.22, we quantified the major components of the PA bouquet of S. officinale ( $\bullet$ Fig. 3 C and D and Fig. 2S, Supporting Information). By GC-MS analysis, we were able to confirm that the 3 most abundant PAs that were quantified by LC-MS were 7-acetylintermedine $\mathrm{N}$-oxide $\left([\mathrm{M}+\mathrm{H}]^{+}\right.$ 358.18), the stereoisomers echiupinine $N$-oxide and myoscorpine $\mathrm{N}$-oxide $\left([\mathrm{M}+\mathrm{H}]^{+} 398.21\right)$, and 3-acetylmyoscorpine $\mathrm{N}$-oxide $\left([\mathrm{M}+\mathrm{H}]^{+}\right.$440.22). These PAs have previously been described as the characteristic PA components of wild-type $S$. officinale HRs [27]. The stoichiometry of these PAs was the same in both the GC-MS- and LC-MS-based analyses. An exemplary GC-MS base peak chromatogram is shown in Fig. 35 (Supporting Information).

LC-MS data revealed that the relative intensity of the mass [M + $\mathrm{H}]^{+} 358.18$ of the PA N-oxide 7-acetylintermedine was significantly reduced in the knockdown mutants compared with the control (hedge's $g=1.34, p=0.004, \sim$ Fig. $3 \mathrm{C}$ ). The less abundant PA-N-oxide, namely 3-acetylmyoscorpine (corresponding mass: $[\mathrm{M}+\mathrm{H}]^{+}$440.22), was also significantly reduced in HSS knockdown mutants (hedge's $g=2.43, p=0.015$, > Fig. $3 \mathrm{D}$ ). The rela- 
tive intensities of both PAs $\left([\mathrm{M}+\mathrm{H}]^{+} 358.18\right.$ and $\left.[\mathrm{M}+\mathrm{H}]^{+} 440.22\right)$ were reduced on average by $60 \%$ in HSS knockdown lines compared with the control lines. This is in the same range of magnitude as the observed downregulation of HSS transcript levels in the tested knockdown lines by 60-80\% ( $\triangleright$ Fig. 2). When testing the correlation between the HSS transcript level and 7-acetylintermedine $\mathrm{N}$-oxide in mutants transformed with the RNAi construct and in control HRs, we found a significantly $(p<0.0001)$ strongly positive correlation (Pearson's product-moment coefficient = 0.85, - Fig. 4B). The same was the case for the less abundant PA (3-acetylmyoscorpine $\mathrm{N}$-oxide [ $\mathrm{p}<0.001]$, Pearson's product-moment coefficient $=0.82$, $>$ Fig. $4 \mathrm{C}$ ). In addition, we found a significant $(p<0.001)$ strong correlation between the third quantified PA specific mass $\left([\mathrm{M}+\mathrm{H}]^{+} 398.21\right.$, echiupinine $\mathrm{N}$-oxide and myoscorpine $\mathrm{N}$-oxide) and the HSS transcript level (Pearson's productmoment coefficient $=0.79$, $\vee$ Fig. 4D), but in contrast to the most abundant PAs, namely 7 -acetylintermedine $\mathrm{N}$-oxide and 3-acetylmyoscorpine $\mathrm{N}$-oxide, only nonsignificant differences were seen between HSS knockdown lines and control lines for these minor PAs (hedge's $g=0.59, p=0.292$, > Fig. $3 \mathrm{E}$ ).

\section{Discussion}

The occurrence of PAs in many plant species, including medicinal plants, has a strong impact on the usability of PA-containing herbal products in pharmacy or make sophisticated purification procedures necessary [28-30]. Strategies to improve the quality of preparations from PA-containing plants require a better understanding of the biology of PA biosynthesis in order that PA biosynthesis can be manipulated in plants directly or in tissue and cell cultures.

Over the last 25 years, several in vitro studies and tracer-feeding experiments have shown that HSS is the first pathway-specific enzyme of PA biosynthesis and produces homospermidine, which is exclusively incorporated into the necine base moiety of PA structures $[9,10,31]$. However, to date, no robust in planta evidence has been available demonstrating that HSS is essential for PA biosynthesis. Because HSS produces the first pathway-specific intermediate homospermidine, HSS is hypothesized to be a regulator of PA biosynthesis and therefore seems to be an ideal target for a gene-knockdown approach in order to reduce PA levels in the plant. In this study, we show that the downregulation of HSS transcript levels by RNAi indeed correlates with reduced amounts of homospermidine and PAs.

We have observed only slight differences in the PA composition between the control HRs in this study and the data published earlier by Frölich et al. [27]. The 3 masses that were quantified in our analysis represent $95 \%$ of the PAs that are typically found in S. officinale HRs. The $\mathrm{N}$-oxide 7 -acetylintermedine $\left([\mathrm{M}+\mathrm{H}]^{+}\right.$ 358.18 ) accounted for $47-62 \%$ of the total PA content quantified in our analysis, which is in accordance with the data of Frölich et al. [27], who described 7-acetylintermedine $\mathrm{N}$-oxide as the most abundant PA in HRs, contributing approximately $56 \%$ to the total PA content (Fig. 1S, Supporting Information). The $\mathrm{N}$-oxide 3 -acetylmyoscorpine $\left([\mathrm{M}+\mathrm{H}]^{+} 440.22\right)$ contributed $19-34 \%$ to the total PA content (Fig. 1S, Supporting Information). Frölich et al. [27] described this compound as accounting for approximately $10 \%$ of total PAs. PA N-oxides with the corresponding mass $[\mathrm{M}+\mathrm{H}]^{+}$ 398.21 (myoscorpine and echiupinine) had the lowest abundance and contributed $15-21 \%$ to the total amount of PAs quantified in our study (Fig. 1S, Supporting Information) and to approximately $20 \%$ of total PA content in the study of Frölich et al. [27].

The relative intensities of the 2 predominant masses $\left([\mathrm{M}+\mathrm{H}]^{+}\right.$ 358.18 and $[\mathrm{M}+\mathrm{H}]^{+}$440.22), representing together the vast majority of PAs detectable in HRs, are significantly reduced in HSS knockdown mutants. These results clearly demonstrate the importance of HSS for PA biosynthesis. Reduced transcript levels indicate reduced levels of gene product (i.e., HSS protein), which should result in a reduction of the first pathway-specific intermediate homospermidine. Our data show that, indeed, reduced levels of homospermidine successfully limit the amount of PAs produced. The observation that the relative intensity of the mass of $[\mathrm{M}+\mathrm{H}]^{+} 398.21$, representing only a minor proportion of PA $\mathrm{N}$ oxide structures present in HRs of $S$. officinale, is only slightly reduced in HSS knockdown lines in comparison to control lines might be attributable to myoscorpine $\mathrm{N}$-oxide and/or echiupinine $\mathrm{N}$-oxide being precursors for their 3-acetyl derivatives $([\mathrm{M}+\mathrm{H}]+$ 440) [27]. When the amount of these precursor PAs is reduced, the acetylation resulting in the 3-actetyl derivatives might be inhibited, which could result in a less strong reduction of the PA content of myoscorpine and/or echiupinine.

The observed reduction of PA levels by roughly $60 \%$ is in the range of that observed in RNAi knockdown experiments in plants synthesizing other groups of alkaloids. DeBoer et al. (2011) [17] have found a similar decrease in nicotine levels of tobacco HRs by suppressing ornithine decarboxylase. Another group has detected decreased amounts of the tanshinones dihydrotanshinone I by $53 \%$ and cryptotanshinone by $38 \%$ in RNAi knockdown HRs of Salvia miltiorrhiza Bunge, Lamiaceae, suppressing copalyldiphosphate synthase [32]. A few studies have also shown that RNAi knockdown of secondary metabolism genes can lead to almost undetectable levels of the respective metabolite $[15,16]$.

The described experimental setup offers various opportunities for future studies: (1) the elucidation of PA biosynthesis by testing candidate genes for their involvement in specific steps of the pathway by gene knockdown and (2) the opportunity to generate PA-reduced or, after further optimization and selection, even PAfree specimens for the production of herbal medicines.

In studies focusing on the elucidation of PA biosynthesis, candidate gene sequences that result for example from differential approaches by using next generation sequencing (e.g., Sievert et al., 2015) can be tested for effects of RNAi-mediated downregulation on PA levels as described here for HSS. In vivo knockdown studies have the advantage that a gene function is studied in an almost unchanged environment and that the effect of a reduced gene product is tested directly in the plant of interest. Many known and unknown factors influencing the gene in vivo, such as co-factors and transcription factors, are included in the experimental setup. In addition to the establishment that a candidate sequence is involved in PA biosynthesis, the accumulation of the intermediate preceding the downregulated enzyme might help to identify this intermediate.

The presence of PAs in medicinal preparations of S. officinale and also of other PA-containing medicinal plants such as Petasites 
hybridus L., Asteraceae [29], restricts the use of such extracts to external applications [1]. For other forms of applications, laborious and cost-intensive purification processes have to be conducted in order to remove PAs efficiently from the prepared extracts [25]. The RNAi-mediated knockdown of HSS or other PA pathway-specific genes might be a way of reducing the PA content without influencing the content of beneficial active components. In S. officinale, these compounds are allantoin and rosmarinic acid, which have not been in the focus of this study.

\section{Materials and Methods}

\section{Plant material}

S. officinale (Rühlemann's Kräuter \& Duftpflanzen) was grown in pots containing a mixture of potting soil (TKS2, Floragard) and lava granulate at a ratio of $3: 1$ in the greenhouse from April to September in the Botanic Gardens of Kiel University (54 $20^{\prime} 45.2^{\prime \prime} \mathrm{N} 10^{\circ} 07^{\prime}$ $\left.05.3^{\prime \prime} \mathrm{E}\right)$. Identity of the species was confirmed by DO. A herbarium sheet of this plant material was placed in the herbarium KIEL with the accession number KIEL0005102. Plants that were used to generate amiRNA mutants were grown in the greenhouse of the Technische Universität Dresden (Dresden, Germany, $51^{\circ} 01^{\prime} 46.0^{\prime \prime} \mathrm{N} 13^{\circ}$ $\left.43^{\prime} 44.1^{\prime \prime} \mathrm{E}\right)$ under light/dark cycles ( $16 \mathrm{~h} / 8 \mathrm{~h}$ ) and $23^{\circ} \mathrm{C} / 18^{\circ} \mathrm{C}$ in soil (Einheitserde Typ P, Hermina-Maier) from March to October.

\section{Cloning of RNAi constructs}

For the cloning of RNAi constructs, we used the Gateway cloning system (Thermo Fisher Scientific). For the target gene, a 226-bplong sequence stretch covering a short part of the 3 '-end of the coding region and parts of the $3^{\prime}$ untranslated region was amplified with specific primers (Table 1S, Supporting Information) that contained attB1/2-sites for homologous recombination with attP1/2-sites in the pDONR221 vector (Thermo Fisher Scientific). Gateway BP Clonase II enzyme mix was used for the integration of PCR products into PDONR221 as recommended by the manufacturer. The resulting plasmids were transformed into chemically competent Escherichia coli TOP10 cells (Thermo Fisher Scientific) for vector propagation. For integration into the binary pH7GWIWG2(II) [33] destination vector, the positive pDONR221 entry construct and the PH7GWIWG2(II) vector were mixed at a molar ratio of $2: 1$, and homologous recombination was carried out with Gateway LR Clonase II Enzyme Mix as suggested by Karimi et al. [34]. To generate control lines of HRs selectable on the antibiotic hygromycin, we used a PH7GWIWG2(II) vector that contained the gus gene in both multiple cloning sites. This guscontaining vector was generated by means of the control plasmid (pENTR-gus) that was shipped with the Gateway LR Clonase Enzyme Mix by using the same cloning strategy as described for the RNAi constructs. Transformation with this plasmid was considered not to cause any RNAi effect because the bacterial gus gene is not present in S. officinale. Plasmids were propagated in E. coli TOP10 cells, and correct insertion was controlled by sequencing at MWG Eurofins.

\section{Cloning of amiRNA constructs}

The amiRNA constructs were designed by using the Web MicroRNA Designer [26]. The artificial miRNA vector pRS300 was purchased from Addgene. The sequences for the artificial miRNA/ miRNA* were miRNA1 TTA TTT AAA TGT CTC ACG CCG/CGA CGT GAG ACA TAT AAA TAT, mIRNA2 TCA AAT GTG ATG CTT AGG CAG/CTA CCT AAG CAT CTC ATT TGT, and miRNA4 TAT TGT CCA TAG CAC TTA CGT/ACA TAA GTG CTA TCG ACA ATT. These were used to exchange the original MIR319a from $A$. thaliana encoded in this vector. The pre-miRNA was further amplified by using overlap PCR with the miRNA-corresponding primers as described by Schwab et al. [19]. Further cloning for transformation into S. officinale HRs via $A$. rhizogenes was performed by using the Gateway cloning system, but with pMDC32 [35] as the destination vector. HSS transcript level quantification, PA content quantification, and growth conditions of amiRNA lines in comparison with control lines are described in the Supporting Information (Supplementary Methods).

\section{Transformation of $A$. rhizogenes}

Binary vectors were transformed into chemically competent A. rhizogenes strain ATCC 15834 (ATCC) [36] cells by the freeze/ thaw method described by Wise et al. [37]. Chemically competent cells were thawed on ice, $2 \mu \mathrm{g}$ plasmid DNA was added, and the mixture was incubated for an additional 30 min on ice. The mixture was then frozen in liquid nitrogen and thawed in a water bath at $37^{\circ} \mathrm{C}$ for approximately $45 \mathrm{~s}$ until completely liquefied. To allow expression of spectinomycin resistance, $1 \mathrm{~mL}$ YEB media $(5 \mathrm{~g} / \mathrm{L}$ beef extract (Carl ROTH), $1 \mathrm{~g} / \mathrm{L}$ yeast extract (Carl ROTH), $5 \mathrm{~g} / \mathrm{L}$ peptone (Carl ROTH), $5 \mathrm{~g} / \mathrm{L}$ sucrose (Carl ROTH), and $0.5 \mathrm{~g} / \mathrm{L}$ $\mathrm{MgSO}_{4}$ (Carl ROTH), $\mathrm{pH} 7$ ) were added, followed by incubation at $28^{\circ} \mathrm{C}$ for $5 \mathrm{~h}$ on a rotary shaker. Cells were streaked out onto solidified YEB media ( $1.5 \%$ agar) containing $100 \mu \mathrm{g} / \mathrm{mL}$ spectinomycin and cultured for $48 \mathrm{~h}$ at $28^{\circ} \mathrm{C}$. Positive colonies were grown for an additional $16 \mathrm{~h}$ in liquid YEB. Stock cultures were stored in YEB media containing $25 \%(\mathrm{v} / \mathrm{v})$ glycerol at $-80^{\circ} \mathrm{C}$ until use.

\section{Generation of transgenic HR mutants}

For the generation of HRs, young leaves (max. $20 \mathrm{~cm}$ length) were harvested and washed with unsterile water supplemented with Tween 20 (0.01\%). Sterilization of the surface was achieved by washing the leaves for $30 \mathrm{~s}$ in $70 \%$ ethanol and for 5 min in calcium hypochlorite $(6 \%[\mathrm{w} / \mathrm{v}]$ solution of a $70 \%[\mathrm{w} / \mathrm{w}]$ powder). After this treatment, the leaves were thoroughly washed 3 times in sterile water. The sterile leaves were cut into pieces with a 2- to $3-\mathrm{cm}$ edge length and co-cultivated with the agrobacteria. A freshly grown overnight culture of $A$. rhizogenes strain ATCC 15834, harboring the respective construct, was centrifuged for $10 \mathrm{~min}$ at $3500 \mathrm{~g}$, the supernatant was discarded, and the cell pellet was re-suspended to a final $\mathrm{OD}_{600}$ of 0.2 in MS media with $20 \%$ of the original amount of $\mathrm{NH}_{4} \mathrm{NO}_{3}$ [38]. The leaf explants were incubated in this Agrobacterium-containing medium for $3 \mathrm{~h}$ at $26^{\circ} \mathrm{C}$ with gentle agitation before being transferred upside down to solid MS20 media ( $1 \%[\mathrm{w} / \mathrm{v}]$ agar). After $3 \mathrm{~d}$ at $23^{\circ} \mathrm{C}$ in the growth chamber (constant light/dark regime of $16 \mathrm{~h}$ of $200 \mu \mathrm{mol} \mathrm{m} \mathrm{m}^{2} / \mathrm{s}$ ), the explants were transferred to solid MS20 media containing $250 \mu \mathrm{g} / \mathrm{mL}$ of a mixture of ticarcillin and clavulanic acid (mixed at 
a ratio of 15:1, Duchefa). The infected explants were cultivated in the growth chamber and transferred to fresh media when growth of the agrobacteria became apparent. Emerging HRs of approximately $1 \mathrm{~cm}$ length were cut from the leaf and transferred to fresh MS20 plates containing ticarcillin, clavulanic acid, and hygromycin B $(25 \mu \mathrm{g} / \mathrm{mL})$ for the selection of successfully transformed HR lines. HR mutants that survived the selection were tested by PCR for the successful integration of the respective constructs into the genome by amplification of the hpt resistance cassette and the rolA gene [39]. The absence of remaining agrobacteria was tested by amplification of the virD gene [40]. When amplification of virD was unsuccessful, the HRs were considered agrobacteria-free. Primers used for PCR analyses are listed in Table 1S (Supporting Information).

\section{HR growth and experimental setup}

For the quantification of homospermidine, PAs, and HSS transcript levels, HR mutants were grown 3 times independently under the same conditions in a climate chamber to give technical replicates. Equal amounts of root material taken from a well-grown HR line were transferred into $70 \mathrm{~mL}$ liquid MS20 media (supplemented with $285 \mu \mathrm{g} / \mathrm{mL}$ ticarcillin/clavulanic acid mixture and $8.5 \mu \mathrm{g} / \mathrm{mL}$ nystatin to prevent growth of agrobacteria or contaminating microorganisms) and grown in the dark at $21^{\circ} \mathrm{C}$ for $14 \mathrm{~d}$ on an orbital shaker at $130 \mathrm{rpm}$. At the end of the experiment, the HRs were patted dry with tissue paper and weighed, and 1 half of the grown roots was freeze-dried for PA extraction. The other half was flashfrozen in liquid nitrogen and stored until transcript quantification at $-80^{\circ} \mathrm{C}$.

\section{Extraction and quantification of homospermidine}

Of the freeze-dried HRs, 10-100 mg were ground, $10 \mu \mathrm{g}$ 1,7-diaminoheptane was added as an internal standard, and the polyamines were extracted with $5 \%(\mathrm{v} / \mathrm{v})$ perchloric acid and freeze-thaw cycles according to Minocha et al. [41]. Subsequently, the $\mathrm{pH}$ was raised to $\mathrm{pH} 11-14$ with $10 \mathrm{M} \mathrm{NaOH}$ (approx. $100 \mu \mathrm{L}$ per $100 \mu \mathrm{L}$ extract). The samples were derivatized in an HPLC autosampler by using an in-needle protocol with 9-fluorenylmethylchloroformate (according to Xiongfeng \& Rohrer [42]) and quantified by using HPLC-UV. Derivatized homospermidine was chromatographed by using an Ultimate 3000 HPLC equipped with an autosampler, quaternary pump, and diode-array detector (Thermo Fisher Scientific). The HPLC conditions were as follows: mobile phase $A=$ acetonitrile, mobile phase $B=40 \mathrm{mM}$ sodium acetate $\mathrm{pH}$, starting conditions $50 \% \mathrm{~A}$ and $50 \% \mathrm{~B}$ isocratic for $15 \mathrm{~min}$, increase of $A$ from $50-60 \%$ over $10 \mathrm{~min}$, from $60-95 \%$ over $35 \mathrm{~min}$, and $95 \%$ A constant for $5 \mathrm{~min}$. The UV chromatogram was recorded at $270 \mathrm{~nm}$. An Accucore XL C18 column (250 mm $\times 3 \mathrm{~mm}, 4 \mu \mathrm{m}$, Thermo Fisher Scientific) was used.

\section{Quantification of PAs}

The freeze-dried material was pulverized with a mortar and pestle. From this material, $10 \mathrm{mg}$ was transferred to $2 \mathrm{~mL}$ reaction tubes and further crushed with metal balls in a Mixer Mill MM 400 (Retsch, 30/s for $1 \mathrm{~min}$ ). PAs were extracted twice at room temperature in $600 \mu \mathrm{L}$ each $80 \%(\mathrm{v} / \mathrm{v})$ methanol containing $0.5 \mu \mathrm{g} /$ $\mathrm{mL}$ PA monocrotaline (Sigma-Aldrich) as an internal standard (first and second extraction for $15 \mathrm{~h}$ and $30 \mathrm{~min}$, respectively, end-overend). After centrifugation for $10 \mathrm{~min}$ at $12,000 \mathrm{~g}$ and $4^{\circ} \mathrm{C}$, the supernatants were combined and transferred into a new tube. Before LC-MS measurements, $40 \mu \mathrm{L} 0.1 \%$ formic acid was added to $160 \mu \mathrm{L}$ sample followed by centrifugation for $1 \mathrm{~min}$ at $12,000 \mathrm{~g}$ and $4{ }^{\circ} \mathrm{C}$ to allow precipitation of potentially remaining substances that were insoluble under LC conditions prior to injection.

To assess LC-MS measurement stability, quality control samples were used following Demetrowitsch et al. [43]. From each sample, $20 \mu \mathrm{L}$ extract was combined and treated in the same way as the original samples (e.g., the same freeze-thaw cycles) and measured repeatedly over the whole LC-MS run. All samples were divided into 3 batches, each containing 1 replicate of cultivation, and each sample was measured 3 times. The measurements were performed on 3 consecutive days on an LC-coupled QTOF-MS system. The components of the extracts were separated on a reversed-phase LC column (Nucleodur C18 Gravity column, $100 \mathrm{~mm} \times 2 \mathrm{~mm}, 1.8 \mu \mathrm{m}$, Macherey\&Nagel) with an Infinity 1260 HPLC system (Agilent Technologies) according to Wesseling et al. [7]: briefly, flow rate: $250 \mu \mathrm{L} / \mathrm{min}$; gradient from $0 \%$ solvent $B$ from minute 1 to $90 \%$ at minute 9 (solvent A: water, $0.1 \%$ formic acid; solvent B: acetonitrile, $0.1 \%$ formic acid). The column was washed with $90 \%$ of solvent B for $30 \mathrm{~s}$ after which the system was equilibrated again for $5 \mathrm{~min}$ and $30 \mathrm{~s}$ under the starting conditions.

A microTOFQII mass spectrometer (Bruker Daltonik) with ESI source was used for mass-to-charge measurements. The positive ionization mode with broadband collision-induced dissociation method (bbCID) was chosen. The parameters were dry gas at $210^{\circ} \mathrm{C}$, flow rate of $6 \mathrm{~L} / \mathrm{min}$, a nebulizer pressure of $100 \mathrm{kPa}$, and an ionization energy of $10 \mathrm{eV}$ for MS and $20 \mathrm{eV}$ for MS/MS.

Relative quantification of PAs was performed with Compass PathwayScreener 1.0 software (Bruker Daltonik). The parameters were: extracted ion chromatogram width of $\pm 5 \mathrm{mDa}$, mSigma tolerance set to 1000 , and the area and intensity threshold set to 100 counts. The minimum peak area was set to $1 \%$ at a sensitivity level of $99 \%$ and a smoothing (Gauss) width of 0.2 (for details, see Wesseling et al. [7]). In the analysis, we focused on the masses $[\mathrm{M}+\mathrm{H}]^{+}$of the PA $\mathrm{N}$-oxides with the highest abundance in S. officinale as reported earlier by Frölich et al. [27]: $[\mathrm{M}+\mathrm{H}]^{+} 358.18$ (7-acetylintermedine), $[\mathrm{M}+\mathrm{H}]^{+} 398.21$ (echiupinine and myoscorpine), and $[\mathrm{M}+\mathrm{H}]^{+} 440.22$ (3-acetylmyoscorpine).

\section{Identification of the quantified PAs by GC-MS}

For explicit identification of the quantified PAs, we extracted PAs from a HR control line for GC-MS analysis. For GC-MS analyses, PA $\mathrm{N}$-oxides have to be transferred to their tertiary form. Therefore, PAs were reduced and extracted as described by Kempf et al. [44]. GC-MS data were obtained with a Thermo TSQ DUO system equipped with an Optima-MN1 column $(30 \mathrm{~m} \times 0.25 \mathrm{~mm}$ i.d., $0.25 \mu \mathrm{m}$ film thickness, Macherey\&Nagel). El-mass spectra were recorded at $70 \mathrm{eV}$ (ion source temperature $200^{\circ} \mathrm{C}$ ). GC conditions were: injector $280^{\circ} \mathrm{C}$, temperature program $80^{\circ} \mathrm{C}$ for $5 \mathrm{~min}, 80-$ $300^{\circ} \mathrm{C}$ at $15^{\circ} \mathrm{C} / \mathrm{min}$, following $5 \mathrm{~min}$ at $300^{\circ} \mathrm{C}$, carrier gas helium $1 \mathrm{~mL} / \mathrm{min}$, MS transfer line $250^{\circ} \mathrm{C}$. Individual PAs were identified by their Kovats indices ( $R_{\mathrm{i}}$ values), molecular ions, and MS fragmentation patterns in comparison with our own comprehensive 
MS data base of PAs. GC-MS data (m/z 50-650) for 7-acetylintermedine were: $R_{i} 2216$ (on MN1), m/z 341 [M+]; MS spectrum, $m / z$ (relative intensity): 180(100), 120(75), 93(72), 136(29), 181(28); for echiupinine: $R_{\mathrm{i}} 2480$, $\mathrm{m} / \mathrm{z} 381$ [ $\mathrm{M}^{+}$]; for myoscorpine: $\mathrm{R}_{\mathrm{i}} 2489$, m/z $381\left[\mathrm{M}^{+}\right]$, MS spectrum, m/z: 220(100), 136(84), 120(67), 83 (53), 93(52); for 3-acetylmyoscorpine: $R_{i} 2554, m / z 423$ [M+], MS spectrum, m/z: 220(100), 136(67), 120(64), 93(58), 83(47). Based on the analyses described in this paper, a distinction between 3-acetylmyoscorpine and 3-acetylechiupine was not possible because of the lack of a reference. Based on previously published data from our group, we assumed the presence of 3-acetylmyoscorpine [45].

\section{RNA extraction and qRT-PCR}

HR samples were pulverized in liquid nitrogen with a mortar and pestle, and total RNA was extracted with Trizol (Life Technologies) according to the manufacturer's protocol including optional steps as previously reported by Kruse et al. [46]. RNA was dissolved in RNAse-free water, and RNA integrity was tested by agarose gel electrophoresis and by 260/280 nm and 260/230 nm ratio measurements by using a NanoDrop ND2000 UV/VIS spectrometer. Reverse transcription was performed with RevertAid Premium Reverse Transcriptase following Kruse et al. [46]. For each sample, 1 control reaction was set up without reverse transcriptase (noRT control) to test for genomic DNA contaminants. The qRT-PCR was performed in a Rotor-Gene Q System (Qiagen) by using GoTaq qPCR Master Mix (Promega) following a protocol described earlier [46]. The $2^{\Delta c t}$ method was employed to calculate transcripts levels [47]. gapdh and ef $1 \alpha$ served as reference genes to normalize the expression levels of HSS. Primers are listed in Table 1S (Supporting Information).

\section{Statistical analyses}

Statistical analyses were performed in R version 3.3.3 [48]. Differences in transcript levels and PA content were first tested for normal distribution by applying the Shapiro-Wilk test, and, if required, data were transformed by using the natural logarithm prior to re-fitting models. The Welch 2-sample t-test was used to compare the relative expression between HSS-RNAi and control lines. Effect sizes, using Hedge's g [49], were calculated to quantify the magnitude of the detected effects. For the interpretation of Hedge's g effect size, small $(<0.2)$, medium $(0.2 \leq \mathrm{g} \leq 0.8)$, and large effects ( $>0.8$ ) were distinguished. Pearson's product correlation was used for correlation testing between various PAs and the HSS transcript level. $\mathrm{R}^{2}$ values were interpreted as follows: $0.1-0.3$ as weak, $0.3-0.6$ as moderate, and $\geq 0.6$ as strong correlations. Statistical analyses were performed by using the packages stats, graphics, and base [48].

\section{Supporting Information}

The design of amiRNAs, their respective HSS transcript level, and PA content can be found in Fig. 1S. Methodological details about transcript quantification, PA quantification, and experimental growth conditions for amiRNA mutant lines are described in Supplementary Methods 1 . The abundance of the predominant PAs in HRs of S. officinale is illustrated in Fig. 2S. A GC-MS base peak chromatogram (50-300 m/z) of a strong cation exchange-solid phase extraction from a HR control line is given in Fig. 3S. Primer sequences used in this manuscript are given in Table 1S.

\section{Acknowledgements}

We thank Dr. Tobias Demetrowitsch for support regarding the LC-MS analysis and also Brigitte Schemmerling and Margret Doose for support in the laboratory. We are grateful to Dr. Jessica Garzke for providing helpful comments on the manuscript. This work was partially supported by a grant from the German Research Foundation (DFG, grant no. OB 162/7-2 to DO), by a grant from the European Social Funds (ESF), and by the Free State of Saxony (project number 080938406) to JLM.

\section{Conflict of Interest}

The authors declare that they have no conflict of interest.

\section{References}

[1] Staiger C. Comfrey: a clinical overview. Phytother Res 2012; 26: 1441 1448

[2] Kommission E. Monographie Symphyti radix (Beinwellwurzel). Bundesanzeiger 1990; 318

[3] Fu PP, Xia Q, Lin G, Chou MW. Pyrrolizidine alkaloids - genotoxicity, metabolism enzymes, metabolic activation, and mechanisms. Drug Metab Rev 2004; 36: 1-55

[4] Hartmann T. From waste products to ecochemicals: fifty years research of plant secondary metabolism. Phytochemistry 2007; 68: 2831-2846

[5] Moghe GD, Kruse LH. The study of plant specialized metabolism: challenges and prospects in the genomics era. Am J Bot 2018; 105: 959-962

[6] Hartmann T, Witte L. Chapter four - Chemistry, Biology and Chemoecology of the Pyrrolizidine Alkaloids. In: Pelletier SW. Alkaloids: Chemical and biological Perspectives. Oxford: Pergamon Press; 1995: 155-233

[7] Wesseling AM, Demetrowitsch T], Schwarz K, Ober D. Variability of pyrrolizidine alkaloid occurrence in species of the grass subfamily Pooideae (Poaceae). Front Plant Sci 2017; 8: 2046

[8] Hartmann T, Ober D. Biosynthesis and Metabolism of Pyrrolizidine Alkaloids in Plants and specialized Insect Herbivores. In: Leeper F], Vederas JC. Biosynthesis. Berlin, Heidelberg: Springer; 2000: 207-243

[9] Böttcher F, Adolph RD, Hartmann T. Homospermidine synthase, the first pathway-specific enzyme in pyrrolizidine alkaloid biosynthesis. Phytochemistry 1993; 32: 679-689

[10] Ober D, Hartmann T. Homospermidine synthase, the first pathway-specific enzyme of pyrrolizidine alkaloid biosynthesis, evolved from deoxyhypusine synthase. Proc Natl Acad Sci 1999; 96: 14777-14782

[11] Ober D, Hartmann T. Deoxyhypusine synthase from tobacco. cDNA isolation, characterization, and bacterial expression of an enzyme with extended substrate specificity. J Biol Chem 1999; 274: 32040-32047

[12] Reimann A, Nurhayati N, Backenköhler A, Ober D. Repeated evolution of the pyrrolizidine alkaloid-mediated defense system in separate angiosperm lineages. Plant Cell Online 2004; 16: 2772-2784

[13] Kaltenegger E, Eich E, Ober D. Evolution of homospermidine synthase in the Convolvulaceae: a story of gene duplication, gene loss, and periods of various selection pressures. Plant Cell Online 2013; 25: 1213-1227

[14] Irmer S, Podzun N, Langel D, Heidemann F, Kaltenegger E, Schemmerling B, Geilfus CM, Zörb C, Ober D. New aspect of plant-rhizobia interaction: alkaloid biosynthesis in Crotalaria depends on nodulation. Proc Natl Acad Sci 2015; 112: 4164-4169

[15] Bayindir Ü, Alfermann AW, Fuss E. Hinokinin biosynthesis in Linum corymbulosum Reichenb. Plant J 2008; 55: 810-820 
[16] Runguphan W, Maresh IJ, O'Connor SE. Silencing of tryptamine biosynthesis for production of nonnatural alkaloids in plant culture. Proc Natl Acad Sci 2009; 106: 13673-13678

[17] DeBoer KD, Dalton HL, Edward FJ, Hamill JD. RNAi-mediated down-regulation of ornithine decarboxylase (ODC) leads to reduced nicotine and increased anatabine levels in transgenic Nicotiana tabacum L. Phytochemistry $2011 ; 72: 344-355$

[18] Song J, Wang Z. RNAi-mediated suppression of the phenylalanine ammonia-lyase gene in Salvia miltiorrhiza causes abnormal phenotypes and a reduction in rosmarinic acid biosynthesis. J Plant Res 2011; 124 : 183-192

[19] Schwab R, Ossowski S, Riester M, Warthmann N, Weigel D. Highly specific gene silencing by artificial microRNAs in Arabidopsis. Plant Cell 2006; 18: 1121-1133

[20] Klee H, Horsch R, Rogers S. Agrobacterium-mediated plant transformation and its further applications to plant biology. Annu Rev Plant Physiol 1987; 38: 467-486

[21] Hwang HH, Gelvin SB, Lai EM. Editorial: "Agrobacterium biology and its application to transgenic plant production." Front Plant Sci 2015; 6: 265

[22] Giri A, Narasu ML. Transgenic hairy roots: recent trends and applications. Biotechnol Adv 2000; 18: 1-22

[23] Oksman-Caldentey KM, Inzé D. Plant cell factories in the post-genomic era: new ways to produce designer secondary metabolites. Trends Plant Sci 2004; 9: 433-440

[24] Georgiev MI, Agostini E, Ludwig-Müller J, Xu J. Genetically transformed roots: from plant disease to biotechnological resource. Trends Biotechnol 2012; 30: 528-537

[25] Ludwig-Müller J, Jahn L, Lippert A, Püschel J, Walter A. Improvement of hairy root cultures and plants by changing biosynthetic pathways leading to pharmaceutical metabolites: strategies and applications. Biotechnol Adv 2014; 32: 1168-1179

[26] Ossowski S, Schwab R, Weigel D. Gene silencing in plants using artificial microRNAs and other small RNAs. Plant J 2008; 53: 674-690

[27] Frölich C, Ober D, Hartmann T. Tissue distribution, core biosynthesis and diversification of pyrrolizidine alkaloids of the lycopsamine type in three Boraginaceae species. Phytochemistry 2007; 68: 1026-1037

[28] EFSA Panel on Contaminants in the Food Chain. Scientific opinion on pyrrolizidine alkaloids in food and feed. EFSA Journal 2011; 9: 2406

[29] Schenk A, Siewert B, Toff S, Drewe J. UPLC TOF MS for sensitive quantification of naturally occurring pyrrolizidine alkaloids in Petasites hybridus extract (Ze 339). J Chromatogr B 2015; 997: 23-29

[30] Moreira R, Pereira D, Valentão P, Andrade P, Moreira R, Pereira DM, Valentão P, Andrade PB. Pyrrolizidine alkaloids: Chemistry, pharmacology, toxicology and food safety. Int J Mol Sci 2018; 19: 1668

[31] Böttcher F, Ober D, Hartmann T. Biosynthesis of pyrrolizidine alkaloids: putrescine and spermidine are essential substrates of enzymatic homospermidine formation. Can J Chem 1994; 72: 80-85

[32] Cheng Q, Su P, Hu Y, He Y, Gao W, Huang L. RNA interference-mediated repression of SmCPS (copalyldiphosphate synthase) expression in hairy roots of Salvia miltiorrhiza causes a decrease of tanshinones and sheds light on the functional role of SmCPS. Biotechnol Lett 2014; 36: 363369
[33] Karimi M, Inzé D, Depicker A. GATEWAYTM vectors for Agrobacterium-mediated plant transformation. Trends Plant Sci 2002; 7: 193-195

[34] Karimi M, Depicker A, Hilson P. Recombinational cloning with plant Gateway vectors. Plant Physiol 2007; 145: 1144-1154

[35] Curtis MD, Grossniklaus U. A gateway cloning vector set for highthroughput functional analysis of genes in planta. Plant Physiol 2003; 133: $462-469$

[36] Kuzma J, Nemecek-Marshall M, Pollock WH, Fall R. Bacteria produce the volatile hydrocarbon isoprene. Curr Microbiol 1995; 30: 97-103

[37] Wise AA, Liu Z, Binns AN. Three Methods for the Introduction of foreign DNA into Agrobacterium. In: Wang K. Agrobacterium Protocols. Totowa, NJ: Humana Press; 2006: 43-54

[38] Sievert C, Beuerle T, Hollmann J, Ober D. Single cell subtractive transcriptomics for identification of cell-specifically expressed candidate genes of pyrrolizidine alkaloid biosynthesis. Phytochemistry 2015; 117 : $17-24$

[39] Alpizar E, Dechamp E, Espeout S, Royer M, Lecouls AC, Nicole M, Bertrand B, Lashermes P, Etienne $\mathrm{H}$. Efficient production of Agrobacterium rhizogenes-transformed roots and composite plants for studying gene expression in coffee roots. Plant Cell Rep 2006; 25: 959-967

[40] Alpizar E, Dechamp E, Lapeyre-Montes F, Guilhaumon C, Bertrand B, Jourdan C, Lashermes P, Etienne H. Agrobacterium rhizogenes-transformed roots of coffee (Coffea arabica): conditions for long-term proliferation, and morphological and molecular characterization. Ann Bot 2008; 101: 929-940

[41] Minocha R, Shortle WC, Long SL, Minocha SC. A rapid and reliable procedure for extraction of cellular polyamines and inorganic ions from plant tissues. J Plant Growth Regul 1994; 13: 187-193

[42] Xiongfeng $\mathrm{H}$, Rohrer ]. Automatic precolumn derivatization for the HPLC determination of aliphatic amines in air. Application Note Thermo Fisher Scientific 2016; 7. Available at https://assets.thermofisher.com/TFSAssets/CMD/Application-Notes/AN-1012-LC-Aliphatic-Amines-AirAN70115-EN.pdf. Accessed August 21, 2019

[43] Demetrowitsch TJ, Petersen B, Keppler JK, Koch A, Schreiber S, Laudes M, Schwarz K. Validation of a two-step quality control approach for a largescale human urine metabolomic study conducted in seven experimental batches with LC/QTOF-MS. Bioanalysis 2015; 7: 103-112

[44] Kempf M, Beuerle T, Bühringer M, Denner M, Trost D, von der Ohe K, Bhavanam VBR, Schreier P. Pyrrolizidine alkaloids in honey: risk analysis by gas chromatography-mass spectrometry. Mol Nutr Food Res 2008; 52: $1193-1200$

[45] Stegemann T, Kruse LH, Brütt M, Ober D. Specific distribution of pyrrolizidine alkaloids in floral parts of comfrey (Symphytum officinale) and its implications for flower ecology. J Chem Ecol 2018; 45: 1-8

[46] Kruse LH, Stegemann T, Sievert C, Ober D. Identification of a second site of pyrrolizidine alkaloid biosynthesis in comfrey to boost plant defense in floral stage. Plant Physiol 2017; 174: 47-55

[47] Schmittgen TD, Livak KJ. Analyzing real-time PCR data by the comparative CT method. Nat Protoc 2008; 3: 1101-1108

[48] The R Project for Statistical Computing. Available at https://www. R-project.org/. Accessed August 21, 2019

[49] Hedges LV. Distribution theory for glass's estimator of effect size and related estimators. J Educ Stat 1981; 6: 107-128 